\title{
THE ROLE OF SOCIAL WORKERS IN PEDIATRIC ONCOLOGY
}

\author{
Tengiz VERULAVA ${ }^{\circledR}$, Tinatin ASATIANI ${ }^{2}$, Beka DANGADZE ${ }^{3}$, Revaz JORBENADZE ${ }^{4}$ \\ ${ }^{1}$ Public Health and Insurance Institute, School of Business, Ilia State University, Tbilisi, Georgia \\ Faculty of Social and Political Sciences, Ivane Javakhishvili Tbilisi State University, Tbilisi, Georgia \\ ${ }^{2}$ Faculty of Social and Political Sciences, Ivane Javakhishvili Tbilisi State University, Tbilisi, Georgia \\ ${ }^{3}$ Health Policy Institute, Tbilisi, Georgia \\ ${ }^{4}$ G. Chapidze Emergency Cardiology Center, Tbilisi, Georgia
}

Received 06 Apr 2019, Accepted 18 May 2019

hitps://doi.org/10.31688/ABMU.2019.54.2.14

\section{Abstract}

Introduction. In the past years, the role of social workers in the oncological disease treatment processes has significantly increased. The role implies supporting patient's psycho-social conditions.

The objective of the study was to study the psycho-social challenges of oncological children and their families and to define a role of social work in this area. Material and methods. As part of a qualitative study, five interviews were conducted with pediatric oncologists, also 15 in-depth interviews with family members of oncological patients and a focus group with $8 \mathrm{mem}$ bers. For the quantitative study, 62 beneficiaries and 12 medical specialists were interviewed.

Results. The children with oncology conditions and their families faced psycho-social challenges and were in need of social workers' support in overcoming those challenges. The study demonstrated a low level of public awareness. There is a lack of information among both doctors and beneficiaries. Both psychologists and social workers are involved in re-socialization of oncological children and they care for the improvement of children's quality of life and support their families.

\section{Résumé}

Le rôle des assistants sociaux en oncologie pédiatrique

Introduction. Ces dernières années, le rôle des travailleurs sociaux dans les processus de traitement des maladies oncologiques a considérablement augmenté. Ce rôle implique de soutenir les conditions psychosociales du patient.

L'objectif de l'étude était d'étudier les défis psychosociaux des enfants oncologiques et de leurs familles et de définir le rôle du travail social dans ce domaine. Materiel et méthodes. Dans le cadre d'une étude qualitative, cinq entretiens ont été menés avec des oncologues pédiatriques, ainsi que 15 entretiens approfondis avec des membres de la famille de patients oncologiques et un groupe de discussion composé de 8 membres. Pour l'étude quantitative, 62 bénéficiaires et 12 médecins spécialistes ont été interrogés.

Résultats. Les enfants atteints de cancer et leurs familles étaient confrontés à des problèmes psychosociaux et avaient besoin de l'aide des assistants sociaux pour les surmonter. L'étude a démontré un faible 
However, there are only a few of such organizations. Therefore, many people who need their support have no chance to take such services.

Conclusions. Implementing the social work in the pediatric oncology will be a major step toward the medical quality standards.

Keywords: pediatric oncology, childhood cancer, social worker.

\section{INTRODUCTION}

Oncological disease is an urgent problem in the modern medicine. In the global mortality rating, malignant tumors are on the second place. In Georgia, $14 \%$ of mortalities are caused by oncological diseases ${ }^{1}$. A main cause of the high mortality rate is the late diagnosis ${ }^{2,3} .60 \%$ of cancer cases are diagnosed on the third and fourth stages ${ }^{4,5}$. The cause is mainly preconditioned by a low awareness level of population ${ }^{6}$.

In the past years, the role of oncology social workers has significantly increased as the main providers of psychosocial services for cancer patients and their families ${ }^{7-9}$. As an effective member of a medical team, social workers participate in multidisciplinary teams and are among the first professionals to listen empathically to the needs and concerns of children and their families ${ }^{10}$. A pediatric oncology social worker has many responsibilities: give assistance, training, advocacy, guidance ${ }^{11}$. Pediatric oncology social workers help families manage day-to-day challenges associated with a cancer diagnosis and its treatment ${ }^{12,13}$. The social worker sees the family members and evaluates with them physician statements ${ }^{14,15}$.

Studies demonstrate that children with oncology problems require a psycho-social support since they need to overcome challenges such as social relations, education, professional development problems and susceptibility to depression ${ }^{16,17}$. In such cases, it is important to assess environmental conditions, to care for the improvement of relations between a person and an environment. Beneficiaries are supported and their quality of life is changed by more active psycho-social consultancy, social psycho-therapy, social networks and resources ${ }^{18}$.

The objective of the study was to identify the psycho-social challenges of oncological children, as well as their families. niveau de sensibilisation du public. Les médecins et les bénéficiaires manquent d'informations. Des psychologues et des travailleurs sociaux participent à la resocialisation des enfants oncologiques. Ils veillent à l'amélioration de la qualité de vie des enfants et soutiennent leur famille. Cependant, il n'existe que quelques-unes de ces organisations. Par conséquent, beaucoup de personnes qui ont besoin de leur soutien n'ont aucune chance de bénéficier de tels services.

Conclusions. La mise en ouvre du travail social en oncologie pédiatrique constituera une étape majeure dans la mise en place des normes de qualité médicale.

Mots-clés: oncologie pédiatrique, cancer infantile, assistante sociale.

\section{Material AND MEthods}

For the study purposes, both quantitative and qualitative methods were used. For the qualitative study, five advanced interviews were conducted with pediatric oncologists (with a 10-15-year experience in the oncology area), 15 in-depth interviews with family members of oncological children and a focus group with 8 members.

For the qualitative study, 62 beneficiaries (family members of oncological patients) and 12 medical specialists (pediatric oncologists) were interviewed. The study was conducted in 3 big cities of Georgia, where population is above 40 thousand (Tbilisi, Kutaisi and Batumi). An enrolment criterion - voluntary desire of the respondents to participate in the study.

One of the limitations of the study is a short period of time. It would be better to study beneficiaries' opinions for a longer period. Furthermore, it would be good to study real effects of working by social workers with pediatric oncology patients. It is a limitation of the study that it covered only Tbilisi, Batumi and Kutaisi. Also, one of the important limitations of this study is that no patients were interviewed. The matter was considered quite an emotional and delicate one. Furthermore, for studies like this one, a long period of time is required for preparing children and also, such children cannot be accessed without parents' permission.

\section{Results}

Majority of responders highlighted the following psycho-social concerns: nervous disorder, insomnia, poor appetite, feeling of unfairness, vulnerability, confusion, protest, difficulty in stress management, concentration problems. 
During interviews, respondents were informed about the role of social workers and potential services they could provide. Respondents unanimously considered the importance of social worker's psycho-social role. They think that the strength and psychological stability provided by social workers could give them more power to manage themselves. A social worker can relieve their daily problems.

Respondents showed willingness to get involved in the following activities: art therapies, pleasant family activities, dance therapy, physical exercise, self-expression, creativity, self-realization. These activities will have a positive effect on their quality of life and will motivate both patients and their families to deal with the disease.

Some difficulties in emotion management were identified in a part of interviews. Although, some of them says that their children became more withdrawn and did not show any initiative. They said that one of the main problems was financing. Treatment of some types of the disease requires huge financing.

"One of the main critical moment occurred when the condition was progressing to the good outcome, but suddenly it turned around and the disease worsened again. We could not find out a reason and it was very difficult to start the treatment process again. We could not realize that there was no accurate prognosis of the disease. "

A factor of religion is important as it gives people endurance to not to give up, not to become desperate, trust and be confident in God. One can say that both the religion and the belief have auspicious effects.

„Our child's recovery is God's grace and God would never will us to give up "- says a father of the child.

„Days are similar like water drops, we are continuously in a mode of expectation, sometimes we are even exhausted but we do not change anything. We will change everything as soon as we feel well ".

These words demonstrate sadness and grief with regard to the recovery expectations. In such a case, it is important to care about a quality of life.

"I think it will be good if a social worker cares for a child, tries to help him in giving simple and easily understandable answers to different questions. "

Social workers were expected to care for children, mediate with doctors, look for the sources of financing for both treatment and rehabilitation, motivating, activating children.

As part of the qualitative study, a focus group with 8 members was conducted. The focused group discussion matters referred to the psycho-social challenges in the pediatric oncology, in particular, an effective involvement of social workers in the process of treatment/rehabilitation, a vision of the family members in problem-solving processes.
The focus group participants said: "After getting a cancer diagnosis, patient's family members get depressed, feel low-spirited as expressed by fear and concern. It is expected worsening of the quality of life, fertility disorders, sexual dysfunction, hair loss, obesity, stigmatization, discrimination, mental health deterioration, that their quality of life will worsen, fertility functions will deteriorate, parents' disregard of their health. "

„A serious deterioration of cancer patients' quality of life can be caused by limiting affordability of painkillers. Such a pain causes patients' psychological distress, depression and fears."

„WHO considers Morphine as an essential medicine for pain management. Although, in low income countries, a level of affordability of the medicine is lower as compared to high income countries".

"It is desirable that at the clinic, where children are being treated, a relevant environment and diverse services are provided, that children can use their free time as they wish. Different events should be held, e.g. exhibitions, concerts, where they will be able to express their skills".

"It is better that a child has no knowledge of his diag. nosis or potential risks in order to protect their psychology. We must not scare a child".

„Cancer makes its dent in the patients. They suffer pain and stress in the process of treatment. One child was prescribed a strict diet. The boy frequently goes to cinema together with his friends. He has to say no to carbonated beverages and chips and he feels sad because of it. He asks his parents to permit him to have his favorite food only once to be happy".

In the interviews conducted with doctors, the main question was about a social worker's involvement in the treatment/rehabilitation process and how could they help a doctor in charge.

As doctors say, according to the Western practices, a clinical social work is a profession that improves patients' quality of life, treatment processes and contributes to recovery. Therefore, in pediatric oncology, a social worker is a reliable section for children as well as their parents. The social worker helps children overcoming a pain stress and sadness, gives hope and promotes expressing their abilities and skills. The social worker cares for maintaining children's existing social relations and establishing new ones. Expert opinions vary about willingness of the society to add a social worker level. A public awareness level of the social worker activities is low.

As part of the quantitative study, 62 patient families were interviewed. The main question referred to the need of social workers' psycho-social support to children with oncological conditions. Furthermore, 12 oncologists were interviewed to define whether 
the social workers' involvement in the treatment process contributes to better effects of the treatment.

The study demonstrated that $71 \%$ of the patient family members thought that a social worker helps a doctor in the process of treatment. The social worker spends more time with patients to study their social environment and helps them overcoming socio-psychological challenges. A social worker has more information on a child condition and it is his/ her professional obligation to care for the welfare of both children and their families.

$98 \%$ of interviewees think that in the process of pediatric treatment, different active groups should be set to help patients in relieving, relaxing, developing creative skills. $67 \%$ of interviewees think that a social worker must be qualified and have a good knowledge of the rights of patients/children. Parents highlight a power of hope, belief and love. Patients are more confident in God rather than in doctors' professionalism or modern technologies. Children aged 8-9 are less concerned with a lack of social networking compared to adults since they usually spend time in their families, close to the family members. On the contrary, patients over 11-12 become estranged from their parents for a while and try to establish new contacts with people.

$41 \%$ of the interviewees are on the third stage of their disease, $29 \%$ - on the second stage, $15 \%$ on the first stage and $15 \%$ - on the fourth stage. Responders assessed a fear factor by a 4-score scale, where 1 meant less fear and 4 - permanent fear. The study demonstrated that with higher stages of the disease, a fear factor increased while at the first and second stages patients' fear factor is lower.

Majority of interviewees agree with the involvement of social workers as an effective way of response to the processes since a shared responsibility and control will decrease potential ethical violations and improve a quality of service. $44 \%$ of interviewees think that a social worker has to have some basic medical knowledge. $41 \%$ of interviewees think that social workers should have some trainings and $15 \%$ think that everything can be learnt through practicing.

$98 \%$ of interviewees gave a positive answer to the question about a need of setting different active groups to promote patients trying their abilities in different fields to help them relieving, relaxing, developing their creativity. $67 \%$ of interviewees think that the main point is that a social worker has a good knowledge of his/her profession and be independent. 25\% think that a social worker must have a knowledge of patient/children rights. However, both a basic medical education and knowledge of modern approaches are very important.
More than half of interviewees think that children's financial support is required most of all from both private and public sectors to help setting warmer and more comfortable environment, more services and possibilities to relieve their hard times. And experienced parents know a value of hope, belief and love in troubles.

The study demonstrated that those patients with recurrent events, had more cautious attitude to the rehabilitation process, they are more cautious and trust more in God than in doctors' professionalism or modern technologies. Children aged 8-9 were less concerned with a lack of social networking compared to adults since they usually spend time in their families, close to the family members. On the contrary, patients over 11-12 become estranged from their parents for a while and try to establish new contacts with people.

\section{Discussion}

The study demonstrated that the children with oncology conditions and their families faced psycho-social challenges and were in need of social workers' support in overcoming those challenges. However, it is still debatable how to develop a social work in the area of medicine. The study demonstrated a low level of public awareness. There is a lack of information among both doctors and beneficiaries and the basic duties and functions of the social workers job are not understood comprehensively. In order to ensure a more active involvement of social workers in the healthcare area, the profession must be more recognizable and understood as well as a more active learning of the Western experience and transformation thereof to our needs.

Currently a social work is being practiced at the Georgian palliative establishments, there are NGO-financed centers where they care for the rehabilitation of children with oncology problems. Both psychologists and social workers are involved in their re-socialization and they care for the improvement of children's quality of life and support their families. However, there are only a few of such organizations. Therefore, many people who need their support have no chance to take such services.

\section{Conclusions}

Implementing the social work in the pediatric oncology will be a major step toward the European medical quality standards. Study results suggest the development of an informal maintenance system, improvement of connection with households 
concerning the illness, and continued supportive services for the family.

\section{Compliance with Ethics Requirements:}

„The authors declare no conflict of interest regarding this article"

„The authors declare that all the procedures and experiments of this study respect the ethical standards in the Helsinki Declaration of 1975, as revised in 2008(5), as well as the national law. Informed consent was obtained from all the patients included in the study"

"No funding for this study"

\section{References}

1. NCDC. Health care, statistical reference. National center for Disease Control, Ministry of Health, Labour and Social Affairs 2017. Tbilisi, Georgia.

2. Verulava T. Health capital, primary health care and economic growth. Eastern Journal of Medicine 2019;24(1):57-62.

3. Asatiani M, Verulava T. Georgian Welfare State: preliminary study based on Esping-Andersen's typology. Economics and Sociology 2017;10(4):21-28.

4. Richardson E, Berdzuli N. Georgia: Health system review. Health Systems in Transition 2017;19(4):1-90.

5. Verulava T, Jincharadze N, Jorbenadze R. Role of primary health care in re-hospitalization of patients with heart failure. Georgian Medical News 2017;264(3):135-139.

6. Verulava T, Jorbenadze R, Dagadze B, Eliava E. Access to ambulatory medicines for the elderly in Georgia. Home Health Care Management $\mathcal{E}$ Practice 2018;31(2):107-112.

7. Smith E, Walsh-Burke K, Cruzan C. Principles of training social workers in oncology. In J. Holland (ed.),
Psycho-oncology 1998; 1061-1068). New York: Oxford University Press.

8. Pockett R, Peate M, Hobbs K, et al. The characteristics of oncology social work in Australia: Implications for workforce planning in integrated cancer care. Asia-Pacific Journal of Clinical Oncology 2016;12(4):444-452.

9. Herschbach P, Keller M. Psicological problems of cancer patients- a cancer distress scrining with a cancer specific questionnarie. British Journal of Cancer 2004; 91:504-5011.

10. Jones B. Pediatric palliative and end of life care: The role of social work in pediatric oncology. Journal of Social Work End of Life Palliate Care 2005;1:35-62.

11. Kandsberger D. Factors influencing the successful utilization of home health care in the treatment of children and adolescents with cancer. Home Health Care Management and Practice 2007;19(6):450-455.

12. Yi J, Kim J, Akter J, Molloy JK, Ah Kim M, Frazier K. Pediatric oncology social workers' experience of compassion fatigue. J Psychosoc Oncol 2018; 19:1-14.

13. Derogatis LR, Morrow GR, Petting J, et al. The prevalence of psychiatric disorders among cancer patients. JAMA 1983; 249:751-757.

14. Hirakawa Y, Chiang C, Uemura MY, Aoyama A. Job satisfaction among Japanese home-visit care workers. Home Health Care Management and Practice 2019; 31(1):3-8.

15. Pieroni AL. Role of the social worker in a children's cancer clinic. Pediatrics 1967;40(3): Suppl:534-6.

16. Lown EA, Phillips F, Schwartz LA, Rosenberg AR, Jones B. Psychosocial follow-up in survivorship as a standard of care in pediatric oncology. Pediatr Blood Cancer 2015;62(5):514584.

17. Judith W, Ross MSW. Social work intervention with families of children with cancer. Social Work in Health Care 1978;3(3): 257-272.

18. Dyeson TB. The home health care social worker: A conduit in the care continuum for older adults. Home Health Care Management and Practice 2004;16(4):290-292. 